\section{Erythropoiesis in a cell population from the early chick blastodisc induced by diffusible product of second cell population}

ONSET of rapid haemoglobin formation in the blood islands of the developing chick blastodisc, both in ovo and in vitro, commences at the stage of the 6- to 7-somite embryo ${ }^{1-4}$ which is normally attained after $28-33 \mathrm{~h}$ of incubation ${ }^{5}$. This phase of haemoglobin formation seems $s^{4,6}$ to reflect a previous covert differentiation of erythroid-progenitor cells distinct from pre-existing erythropoietic cells which form small quantities of haemoglobin as early as the primitive streak stage of development-after about $20 \mathrm{~h}$ incubation ${ }^{5}$.

$\mathrm{We}^{6}$ have recently developed procedures for the isolation from dispersed single-cell suspensions of primitive streak and head-fold blastodiscs of two distinct cell populations which form foci of erythropoiesis readily visible to the naked eye when incubated as cell reaggregates. One of these populations was further resolved into two discrete essential subpopulations. Aggregates of either of the individual subpopulations tested singly formed no detectable haemoglobin, whereas aggregates formed by remixing portions of the resolved subpopulations were strongly erythropoietic ${ }^{6}$.

As a first approach to defining the nature of the interaction between these two subpopulations we have now determined that direct contact between them is not required. Rather, one of the subpopulations contains progenitors of cells of the erythropoietic series which differentiate into erythroid cells in response to diffusible product(s) of the complementary subpopulation.

Blastodiscs of the Shaver Starcross No. 288 line of White Leghorn fowl were explanted on to a solid minimal medium $^{3}$ and those at the primitive streak and head-fold stages of development were selected for these experiments. They were detached from their supporting vitelline membranes and dispersed by incubation with gentle agitation for a total of $20 \mathrm{~min}$ in $125 \mu \mathrm{l}$ per blastodisc of minimal medium containing 40 units $\mathrm{ml}^{-1}$ of collagenase (Sigma Chemical Company, Type I) and 50 units $\mathrm{ml}^{-1}$ of hyaluronidase (Sigma Chemical Company, Type I). Dispersion was facilitated by gentle flushing with a Pasteur pipette at 10 and $20 \mathrm{~min}$ of incubation. Suspensions of single cells were recovered by filtration through one layer each of Nitex No. 73 (Thompson and Co., Montreal) and Nitex No. 53 nylon monofilament cloth.

Volumes $(1.2 \mathrm{ml})$ of suspension containing $1.2 \times 10^{7}$ cells $\mathrm{ml}^{-1}$ were layered on to freshly-prepared, sterile discontinuous density gradients of Ficoll in liquid minimal medium, at room temperature. These consisted of a $1.3 \mathrm{ml}$ upper layer of solution of specific gravity 1.044, a $1.3 \mathrm{ml}$ intermediate layer of specific gravity 1.049, and a $1 \mathrm{ml}$ cushion of specific gravity 1.062. These gradients were immediately centrifuged in Spinco SW 50 rotors at 4,500 r.p.m. for $30 \mathrm{~min}$ without braking. Cells retained at the upper (subpopulation A) and lower (subpopulation B) interfaces, respectively, of the upper Ficoll band of the gradient were each transferred to $5 \mathrm{ml}$ of minimal medium $-2 \%$ foetal calf serum (Gibco, Grand Island, New York) and sedimented at $5,800 \mathrm{~g}$ for $10 \mathrm{~min}$.

The pellet of subpopulation A was plated with a sterile microspatula on a portion of vitelline membrane laid on the surface of egg homogenate medium ${ }^{7}$, freshly prepared and prewarmed. A layer of dialysis membrane sterilised by autoclaving in distilled water, then equilibrated with Earle's minimal medium containing HEPES buffer (Gibco, Grand Island) and $20 \%$ foetal calf serum, was placed over this aggregate and extending beyond it for at least $2 \mathrm{~cm}$ on all sides. The pellet of subpopulation $B$ was then plated on the dialysis membrane, and the whole was incubated at $38^{\circ} \mathrm{C}$ in a moist chamber.

At $4 \mathrm{~d}$ the upper aggregate of subpopulation $\mathrm{B}$ was seen to be 'peppered' throughout with foci of erythropoiesis readily visible to the naked eye. By contrast, neither the lower aggregate of subpopulation A nor control aggregates of subpopulation B plated alone on dialysis membrane contained any visible haemoglobin.

This result clearly establishes that the two resolved cell populations play different roles in the differentiation of cells of the erythropoietic line. Moreover, they demonstrate that the progenitors present in subpopulation B differentiate to erythroid cells in response to diffusible material(s) of low molecular weight produced by cells in the complementary subpopulation A.

Miura and Wilt $^{8}$ have previously demonstrated that haemoglobin formation in cells of the mesodermal layer of the primitive chick blastodisc is dependent upon material from cells of the endoderm layer which can diffuse through a Millipore filter. It is therefore tempting to suppose that the essential cells of our subpopulations $\mathbf{A}$ and $\mathbf{B}$ are derived from the endoderm and mesoderm, respectively. The relationships between the resolved subpopulations and those inferred to be present in the intact blastodisc however remain to be established.

This work was supported by a grant from the Medical Research Council. We thank Miss N. N. McGrath for technical assistance. S.D.W. is an associate of the Medical Research Council.

\section{S. D. WAINWRIGHT}

LILLIAN K. WAINWRIGHT

Biochemistry Department, Dalhousie University, and Biology Department, Mount St Vincent University, Halifax, Nova Scotia, Canada

Received August 5; revised September 17, 1974.

${ }^{1}$ Wilt, F. H.. Proc. natn. Acad. Sci. U.S.A., 48, 1582-1590 (1962).

${ }^{2}$ Granick, S., and Levere, R. D., J. Cell Biol., 26, 167-176 (1965).

${ }^{3}$ Wainwright, S. D., and Wainwright, L. K., Can. J. Biochem., 44. $1543-1560$ (1966).

${ }^{4}$ Wainwright, S. D., and Wainwright, L. K., Can. J. Biochem., 50. 1165-1173 (1972)

s Hamburger, V., and Hamilton, H. L., J. Morph., 88, 49-92 (1951).

${ }^{6}$ Wainwright, S. D., and Wainwright, L. K., Expl Cell Res. (in the press).

${ }^{7}$ Soratt, N. T., and Haas, H., J. exp. Zool., 144, 139-157 (1960).

${ }^{8}$ Miura, Y., and Wilt, F. H., Devl Biol., 19, 201-211 (1969).

\section{Preparation of human placental villous surface membrane}

THERE is currently considerable interest in the mechanism of protection of the foetus against rejection by the mother ${ }^{2}$. Various theories have been put forward to explain this phenomenon, including the existence of an immunologically inert barrier between mother and foetus ${ }^{2}$, and a reduction of immunological reactivity of the mother during pregnancy ${ }^{3}$. A further possibility is that a hormone such as progesterone binds to the external villous surface of the placenta and masks its antigenicity.

The surface membrane of human chorionic villi represents the effective foeto-maternal junction and therefore a preparation of this membrane would be of value in studying the immunochemistry of the foeto-maternal relationship. We have used a simple saline extraction technique to remove this material from placenta and have studied its composition by electron microscopy. It is likely to contain any antigenic material present as a somewhat similar technique (hypotonic solutions, $0.1-0.8 \%$ ) was used by Davies ${ }^{4}$ in the preparation of membrane fragments rich in $\mathrm{H}-2$ antigenic activity from cell surfaces of mouse spleen and thymus. 